\title{
Research on Gear Shifting Process without Disengaging Clutch for a Parallel Hybrid Electric Vehicle Equipped with AMT
}

\author{
Hui-Long Yu, ${ }^{1,2}$ Jun-Qiang Xi, ${ }^{1}$ Feng-qi Zhang, ${ }^{1}$ and Yu-hui Hu ${ }^{1}$ \\ ${ }^{1}$ State Key Laboratory of Vehicle Transmission, Beijing Institute of Technology, Beijing 100081, China \\ ${ }^{2}$ Department of Mechanical Engineering, Politecnico di Milano, Campus Bovisa, Via La Masa 1, 20156 Milano, Italy \\ Correspondence should be addressed to Jun-Qiang Xi; xijunqiang@bit.edu.cn
}

Received 31 October 2013; Revised 13 December 2013; Accepted 13 December 2013; Published 11 February 2014

Academic Editor: Hamid Reza Karimi

Copyright (c) 2014 Hui-Long Yu et al. This is an open access article distributed under the Creative Commons Attribution License, which permits unrestricted use, distribution, and reproduction in any medium, provided the original work is properly cited.

\begin{abstract}
Dynamic models of a single-shaft parallel hybrid electric vehicle (HEV) equipped with automated mechanical transmission (AMT) were described in different working stages during a gear shifting process without disengaging clutch. Parameters affecting the gear shifting time, components life, and gear shifting jerk in different transient states during a gear shifting process were deeply analyzed. The mathematical models considering the detailed synchronizer working process which can explain the gear shifting failure, long time gear shifting, and frequent synchronizer failure phenomenon in HEV were derived. Dynamic coordinated control strategy of the engine, motor, and actuators in different transient states considering the detailed working stages of synchronizer in a gear shifting process of a HEV is for the first time innovatively proposed according to the state of art references. Bench test and real road test results show that the proposed control strategy can improve the gear shifting quality in all its evaluation indexes significantly.
\end{abstract}

\section{Introduction}

Auto gearshift can help to improve the driving comfort, reduce the friction of clutch and synchronizer, and achieve a better handling of driving even in a complex environment. For instance, drivers having little driving experience may have a bad driving performance or a dangerous accident due to their unskilled operating in a manual gear shifting process [1]. Compared with other common automatic shift technologies, including AT, CVT, and DCT, AMT has lower cost and higher transmission efficiency. Furthermore, it can undertake modification on the traditional transmissions. Therefore, it is used more widely in passenger cars, especially in the hybrid and pure electric vehicles [2].

The main concern of this paper is a single-shaft parallel hybrid electric vehicle equipped with AMT. The structure diagram of the HEV powertrain adopted in this paper is shown in Figure 1. The system is composed of a diesel engine $(172 \mathrm{~kW})$, a permanent magnetic motor (PMSM $75 \mathrm{~kW})$, a clutch, and a 5-speed automated mechanical gearbox. To obtain a smooth, quick, and successful gearshift, the engine, motor, and actuator of the gearbox should be coordinately, controlled very well.

Most of the gearshift control strategies in traditional vehicles equipped with AMT disengage the clutch during a gear shifting process [3-5], which can introduce longtime power interruption and friction of the clutch. A few researchers proposed gearshift control strategies without disengaging the clutch using active engine control $[6,7]$, but the conditions have not been significantly improved due to the slow response of engine. The introduction of driving motor on the HEV gives chance to achieve a fast and smooth gearshift by its active control due to its good response [810].

\section{Gear Shifting Process without Disengaging Clutch in the Hybrid Electric Vehicle}

The gear shifting process is shown as in Figure 2. Typical gear shifting process without disengaging clutch in a parallel hybrid electric vehicle can be divided into the following 
TABLE 1: Parameters of the researched HEV.

\begin{tabular}{lcccccr}
\hline$J_{e}$ & $J_{m}$ & $J_{\mathrm{ci}}$ & $J_{\mathrm{co}}$ & $J_{i}$ & $J_{o}$ & $T_{f-\text { static }}$ \\
\hline $1.2 \mathrm{~kg} \cdot \mathrm{m}^{2}$ & $0.24 \mathrm{~kg} \cdot \mathrm{m}^{2}$ & $0.3 \mathrm{~kg} \cdot \mathrm{m}^{2}$ & $0.028 \mathrm{~kg} \cdot \mathrm{m}^{2}$ & $0.09 \mathrm{~kg} \cdot \mathrm{m}^{2}$ & $0.015 \mathrm{~kg} \cdot \mathrm{m}^{2}$ & $80 \mathrm{~N} \cdot \mathrm{m}$ \\
\hline
\end{tabular}

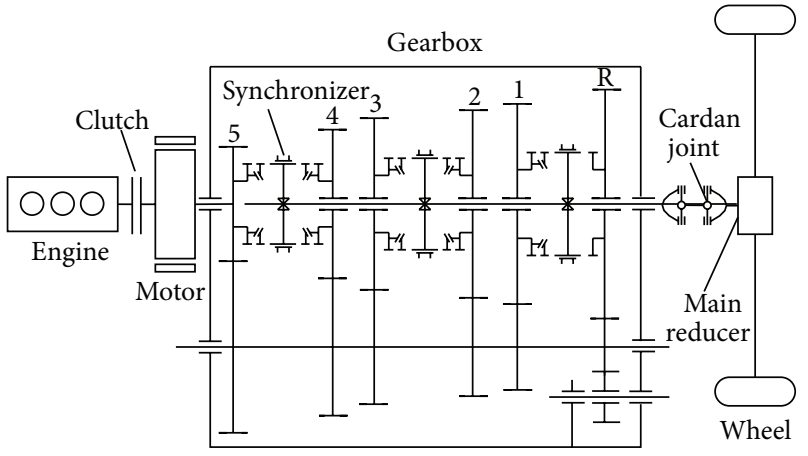

FIGURE 1: Configuration of the researched single-shaft parallel hybrid electric vehicle.

detailed stages: (1) unload of the power sources before a gearshift, (2) switch to neutral gear, (3) active speed synchronization by the motor, (4) mechanical speed synchronization by the synchronizer, (5) selection and engagement the new gears and (6) torque recovery.

The control in stage (1) is mainly aimed at reducing the transmitted torque between the engaged gears close to zero, which means that the power sources are not output driving torque and at the meantime are not driven by the output shaft. Several problems will come out when trying to disengage the gears transmitting large torque as follows.

(a) It is difficult to disengage the gears or damage the teeth surface of the gears due to the contact pressure between the meshing teeth.

(b) It introduces torsional vibration of the output shaft and affects the comfort of the vehicle due to the step change of torque.

(c) It increases the difficulty of active synchronization due to the introduced vibration of output shaft speed.

A gearshift when incompletely unloaded is shown in Figure 3. The main control difficulty in stage (1) is that there is no sensor to measure the transmission torque between the meshing teeth, so it is easy to unload the power sources incompletely or excessively and introduce reverse torque exerted to the input shaft. This phenomenon becomes more frequent when the driver needs a snap acceleration or a quick slowdown; it seriously affects the gear shifting quality.

Stag (3) is the active speed synchronization period; it needs to adjust the speed of the input shaft to a desired speed quickly without overshoot and oscillation; the response of active speed synchronization driven by the PMSM is much faster than that driven by engine [11].

In real driving cycles, stages (4) and (5) which were conduct at the same time were also crucial to obtain a high quality gear shifting process. These two stages in HEV are quite different from those in the traditional vehicles. Rotational inertia of input components of the gearbox in a gearshift without disengaging clutch on a HEV is about 30 times larger than that of those on a traditional vehicle in a gearshift with disengaging clutch, and there is at least a fivefold friction torque increase which can be seen from Table 1 .

We also found that there were frequent phenomena of gear engaging failure or long time gear engaging after synchronization, especially when the road condition changed or there was a braking. The synchronizer wear was serious and the obtained gearshift quality was quite poor. To the best of our knowledge, there is no relative research on this problem.

\section{Evaluation Indexes of Gear Shifting Quality}

3.1. The Gear Shifting Time. The gear shifting time of the single-shaft parallel hybrid electric vehicle includes the unload time $t_{\text {unload }}$, time of disengaging the gear $t_{\text {diseng, }}$, time of active synchronization $t_{\mathrm{PMSM}}$, time of mechanical synchronization and gear engaging $t_{\text {eng }}$, and time of torque recovery $t_{\text {recv }}$. The gear shifting time will affect the dynamics and comfort performance of the HEV.

$$
t_{\text {shift }}=t_{\text {unload }}+t_{\text {diseng }}+t_{\text {PMSM }}+t_{\text {eng }}+t_{\text {recv }} \text {. }
$$

3.2. The Friction Work. The friction work can reflect the wear of the friction pair; it is an important index of durability. The smaller the friction work is the longer the life of synchronizer can be obtained.

The friction work $L$ is given as

$$
L=\int_{0}^{t_{s}} T_{s}\left|\omega_{o}-\frac{\omega_{i}}{i_{g}}\right| d t,
$$

where $t_{s}$ is the friction time, $T_{s}$ is the friction torque, $\omega_{i}, \omega_{o}$ are the angular speed of input part and output part of the friction pairs, respectively [12].

3.3. The Gear Shifting Jerk. The jerk is derivative of longitudinal acceleration; it can reflect the oscillation of driving torque and can be expressed as

$$
j=\frac{d^{2} v}{d t^{2}}=\frac{r}{i_{0}} \frac{d^{2} \omega_{o}}{d t^{2}},
$$

where $t$ is time, $v$ is the vehicle speed, $i_{0}$ is the gear ratio of the main retarder, and $r$ is the radius of the driving wheel. 


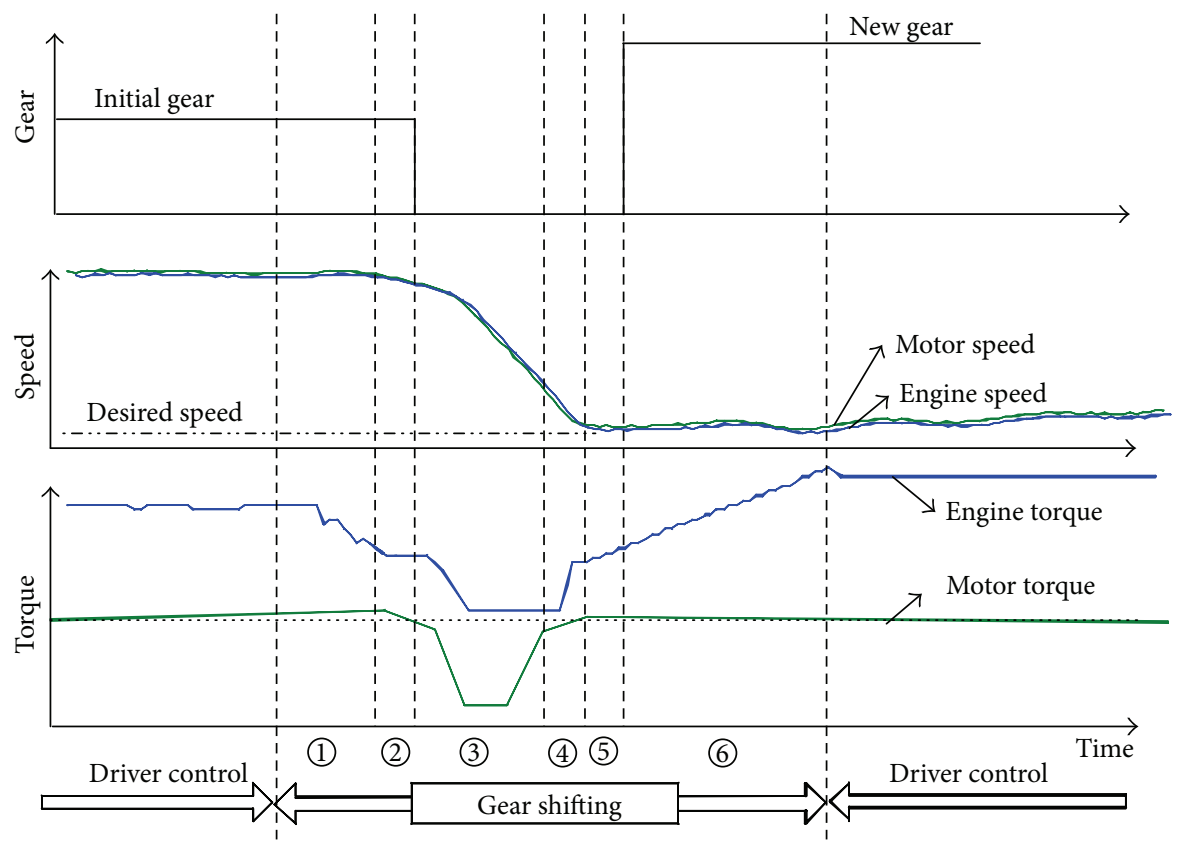

FIGURE 2: Gear shifting process without disengaging clutch of the HEV.

To calculate the jerk equation (3) can be discretized as

$$
\begin{aligned}
j(n) & =\frac{r}{i_{0}} \frac{\left(\omega_{n+2}-\omega_{n+1}\right)-\left(\omega_{n+1}-\omega_{n}\right)}{\Delta t^{2}} \\
& =\frac{2 \pi r}{60 i_{0}} \frac{\left(n_{n+2}-n_{n+1}\right)-\left(n_{n+1}-n_{n}\right)}{\Delta t^{2}},
\end{aligned}
$$

where $n$ is the angular speed of the output shaft. The ride comfort of the vehicle becomes worse than the increase of the jerk. For the quantitative criteria of jerk, the recommended value of Germany is $|j| \leq 10 \mathrm{~m} / \mathrm{s}^{3}$, the one of former Soviet union is: $|j| \leq 31.36 \mathrm{~m} / \mathrm{s}^{3}$, and the one of China is $|j| \leq$ $17.64 \mathrm{~m} / \mathrm{s}^{3}[13]$.

\section{Power Transmission System Modeling}

The sketch of power transmission system for the researched single-shaft parallel hybrid electric vehicle is shown in Figure 4. It should be able to find out the main factors affecting the gear shifting quality in stages (1), (4), and (5). The rotational inertia of clutch is equaled to the permanent magnet synchronous motor due to the fact that there is no clutch disengaging in the gear shifting process. To analyze the torsional vibration of shafts between the driving motor and engine, the torsion between gearbox and final drive is taken into account. The torsion inside the gearbox is ignored.
When the system is in a certain gear, the differential equations are

$$
\begin{aligned}
& \left(T_{e}+T_{m}-T_{e m}-T_{f}\right) i_{g}-T_{o w}-\frac{T_{r}}{i_{o}} \\
& =\left(J_{e} \dot{\omega}_{e}+J_{m+c} \dot{\omega}_{m}+J_{i} \dot{\omega}_{i}\right) i_{g}+J_{o} \dot{\omega}_{o}+J_{w} \dot{\omega}_{w} .
\end{aligned}
$$

When the system is in neutral gear, the differential equations are

$$
\begin{gathered}
T_{e}+T_{m}-T_{e m}-T_{f}=J_{e} \dot{\omega}_{e}+J_{m+c} \dot{\omega}_{m}+J_{i} \dot{\omega}_{i}, \\
-T_{o w}-\frac{T_{r}}{i_{o}}=J_{o} \dot{\omega}_{o}+J_{w} \dot{\omega}_{w} .
\end{gathered}
$$

When the system transforms from neutral gear to a certain gear, the differential equations are

$$
\begin{gathered}
T_{e}+T_{m}-T_{e m}-T_{f}-\frac{T_{s}}{i_{g}}=J_{e} \dot{\omega}_{e}+J_{m+c} \dot{\omega}_{m}+J_{i} \dot{\omega}_{i}, \\
T_{s}-T_{o v}-\frac{T_{r}}{i_{o}}=J_{o} \dot{\omega}_{o}+J_{w} \dot{\omega}_{w},
\end{gathered}
$$

where

$$
\begin{gathered}
T_{e m}=k_{e m}\left(\theta_{e}-\theta_{m}\right)+c\left(\omega_{e}-\omega_{m}\right), \\
T_{o v}=k_{o v}\left(\theta_{o}-\theta_{v}\right)+c\left(\omega_{o}-\omega_{v}\right), \\
\dot{\theta}_{x}=\omega_{x}, \quad x=(e, m, o, v), \\
\frac{T_{r}}{r_{w}}=G\left(f_{\text {road }} \cos \theta+\sin \theta\right)+\frac{C_{D} A v_{a}^{2}}{21.15},
\end{gathered}
$$




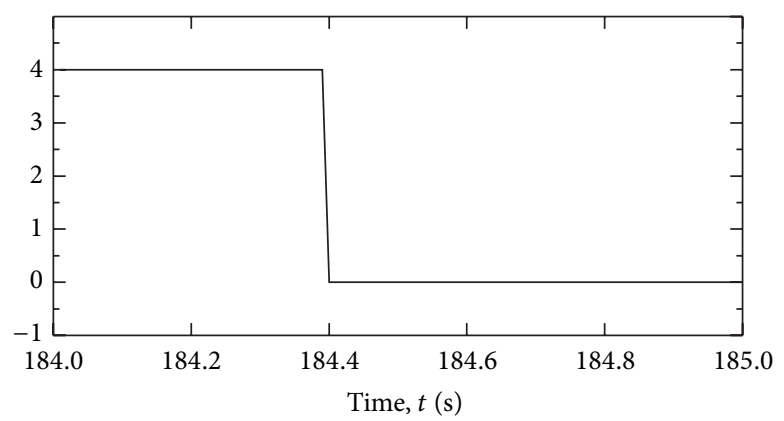

— Current gear

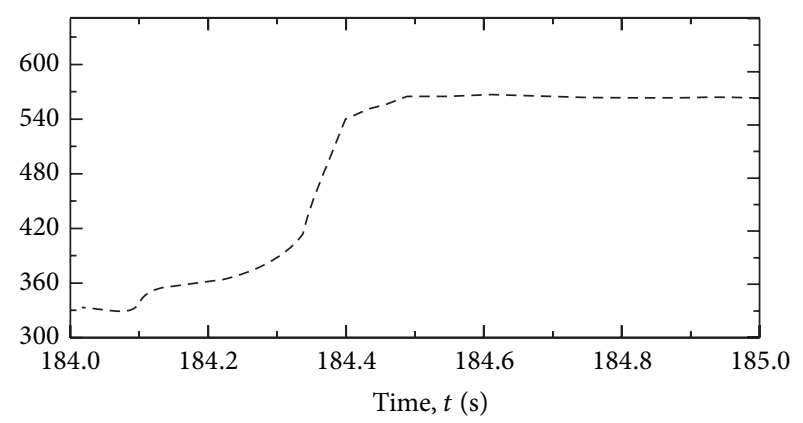

- - - Displacement of gearshift actuator

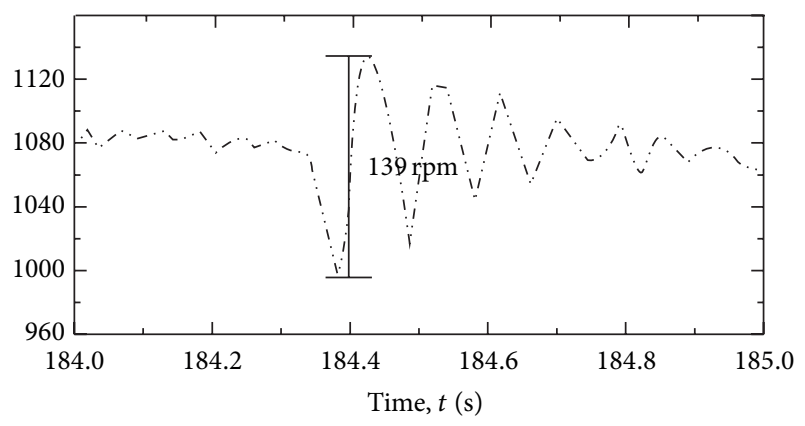

...... Speed of output shaft

Figure 3: A gearshift when incompletely unloaded.

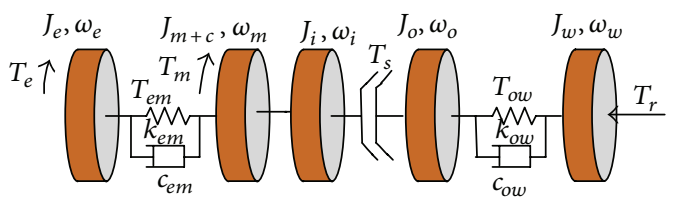

FIGURE 4: Sketch of the power transmission system.

where $T_{e}$ is the output torque of engine, $T_{m}$ is the output torque of driven motor, $T_{e m}$ is the viscoelastic torque of the shaft between motor and engine, $T_{f}$ is the rotating friction torque of transmission input side (including the friction torque of engine, motor, and input shaft) when the clutch is engaged, $T_{o v}$ is the rotating friction torque between transmission output shaft and final drive, $T_{r}$ is the resisting torque of road, $T_{s}$ is the friction torque of synchronizer, $r_{w}$ is the radius of wheel, $i_{g}$ is the transmission ratio, $i_{o}$ is

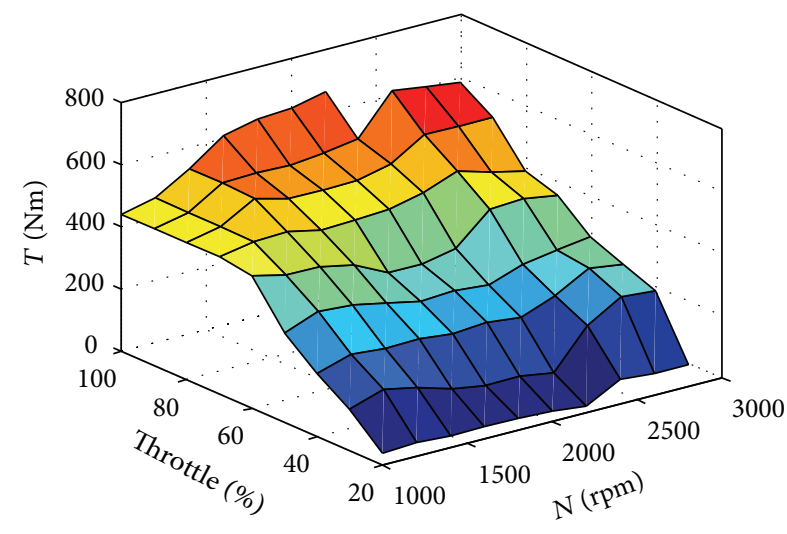

Figure 5: Engine MAP.

the final drive ratio, $\omega_{e}$ is the engine speed, $\omega_{m}$ is the motor speed, $\omega_{i}$ is the transmission input shaft speed, $\omega_{o}$ is the transmission output shaft speed, $\theta_{e}$ is the engine rotation angle, $\theta_{m}$ is the motor rotation angle, $\theta_{o}$ is the rotation angle of transmission output shaft, $\theta_{v}$ is the rotation angle of final drive, $G$ is the vehicle gravity, $f_{\text {road }}$ is the rolling resistance coefficient, $\theta$ is the road slope angle, $C_{D}$ is the air resistance coefficient, $A$ is the face area $\left(\mathrm{m}^{2}\right), v_{a}$ is the relative velocity $(\mathrm{km} / \mathrm{h})$, which represents wind-free velocity, $J_{i}$ is the equivalent rotational inertia of first-speed gear and secondspeed gear in transmission which is converted to the input end of synchronizer, $J_{e+c}$ is the equivalent rotational inertia of engine crankshaft and clutch pressure plate, and $J_{m+c}$ is the equivalent rotational inertia of motor and driven part of clutch.

\section{Components Modeling}

There are two working states of the transmission, in a certain gear or in neutral gear. When it is in neutral gear, $T_{s}=0$. This paper focuses on the research of the switching process between states 1 and 2 . It involves the dynamic process of each component.

5.1. Engine Modeling. The engine torque $T_{e}$ can be obtained from the engine MAP as follows:

$$
T_{e}=f\left(\alpha_{e}, n_{e}\right),
$$

where $\alpha_{e}$ is the engine throttle opening and $n_{e}$ is the engine speed. The engine MAP is shown in Figure 5.

5.2. PMSM Modeling. The transient value of three-phase voltage and current of the motor can be ignored because the time constant of motor torque is generally very small, so the driving motor model can be simplified. Considering the demand torque $T_{m \text {,req }}$, the maximum allowable drive and brake torque of motor with current rotating speed $T_{m \text {,dis }}$ and $T_{m, \text { chg }}$, and the maximum allowable torque of motor when 


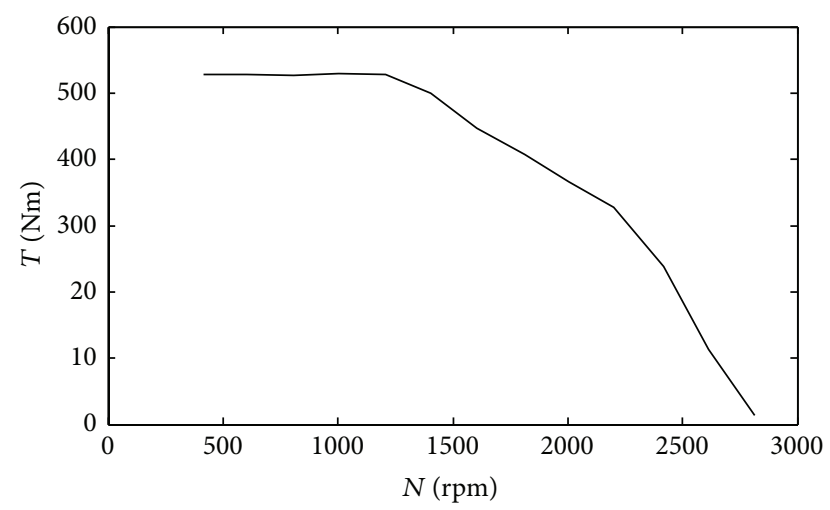

Figure 6: Motor MAP.

the power battery discharges and recharges $T_{b \text {, dis }}$ and $T_{b \text {,chg, }}$, the motor torque can be represented as

$$
T_{m}= \begin{cases}\max \left(T_{m, \text { req }}, T_{m, \text { dis }}, T_{b, \text { dis }}\right) & \text { when } T_{m, \text { req }}>0 \\ \max \left(T_{m, \text { req }}, T_{m, \text { chg }}, T_{b, \text { chg }}\right) & \text { when } T_{m, \text { req }}<0\end{cases}
$$

The motor MAP is shown in Figure 6.

5.3. Gear Shifting Actuator Modeling. The gear shifting actuator is driven by brushless DC motor (BLDCM). In a gear shifting process, parameters including the displacement of actuator and gear shifting force should be under control. The displacement should be tuned to a certain position rapidly and accurately. The output force of the BLDCM also should be accurately controlled.

The mathematical model and torque characteristics of BLDCM can be analyzed with the mode of 3-phase 6-state. At any moment, only two phases work and the remaining one shuts down. The motor adopts Y connection with nonsalient pole. Based on the physical structure, we assume that the three phases of stator are completely symmetrical, the airgap magnetic field produced by rotor is square wave, the back electromotive force of 3-phase winding is trapezoidal wave, the armature reaction of stator winding and eddy current loss are ignored, and the magnetic circuit is not saturated. So the balance equation of the 3-phase stator voltage is given as

$$
u_{k}=R_{s} i_{k}+e_{k}+\left(L_{s}-L_{m}\right) \frac{d i_{k}}{d t}, \quad k=a, b, c .
$$

Leaving out the mechanical loss of rotor and assuming the electromagnetic power can totally translate to the kinetic energy of rotor, the electromagnetic torque of motor is

$$
T_{\mathrm{eg}}=\frac{\left(e_{a} i_{a}+e_{b} i_{b}+e_{c} i_{c}\right)}{\omega_{\text {mech }}}
$$

The kinetic equation of BLDCM is

$$
T_{\mathrm{eg}}=J \frac{d \omega_{m}}{d t}+T_{L}+B \omega_{\mathrm{mech}}
$$

The speed of BLDCM $n$ can be represented as

$$
n=\frac{60 \omega_{\mathrm{mech}}}{2 \pi} \text {. }
$$

The axial force acting on shift sleeve $F_{x}$ can be represented as

$$
F_{x}=T_{\mathrm{eg}} i_{m} \eta_{m}
$$

where $i_{a}, i_{b}, i_{c}$ are phase currents, $u_{a}, u_{b}, u_{c}$ are phase voltages, $R_{s}$ is the phase resistance of stator, $e_{a}, e_{b}, e_{c}$ are phase potential, $L_{s}$ is the self-inductance of stator phase, $L_{m}$ is the mutual-inductor of stator phases, $T_{L}$ is the load torque of motor, $B$ is the damping coefficient, $\omega_{\text {mech }}$ is the angular speed of rotor, $J$ is the rotational inertia of motor, $i_{m}$ is the speed ratio between motor and sleeve operating mechanism, and $\eta_{m}$ is the mechanical efficiency between motor and sleeve operating mechanism.

5.4. Synchronizer Modeling. Synchronizer is one of the most important parts of transmission. The working process of synchronizer directly affects the gear shifting quality [14]. To derive the optimal coordinated control strategy of each part, the operating process of synchronizer is divided into five stages.

5.4.1. First Free Fly. This stage actually includes two processes. First, the sleeve moves forward axially without resistance and pushes the synchro ring to the target gear. The resistance axial force is very small in this stage. Second, the force transfers from sleeve to the sliders, then to the cone surfaces of synchro ring. The spring of slider here is used to keep the balance. When the force transferred increases to a certain extent, the limiting mechanism will lose its balance. So the sliders are pushed into grooves of the synchro hub by the radial pressure, and the sleeve can continue sliding forward. Then the spline teeth of sleeve is contacted to the spline teeth of synchro ring, and the axial force transfers from sleeve to the synchro ring. The schematic diagram of this stage is shown as Figure 7.

The kinetic equation is

$$
F_{x}-F_{f}-F_{r}=m_{s} \dot{a}_{s},
$$

where $m_{s}$ is the mass of sleeve, $\dot{a}_{s}$ is the acceleration of sleeve, $F_{f}$ is the sliding resistance when sleeve moves, and $F_{r}$ is the force acted on sleeve from limiting mechanism.

5.4.2. Angular Velocity Synchronization. The sleeve stops sliding, and its axial velocity becomes zero. The friction between mesh teeth of sleeve and mesh teeth of synchro ring starts to increase while the kinetic energy of sleeve and the target gear begin to decrease. The angular velocity difference between them decreases gradually to zero. The schematic diagram of this stage is shown in Figure 8. 


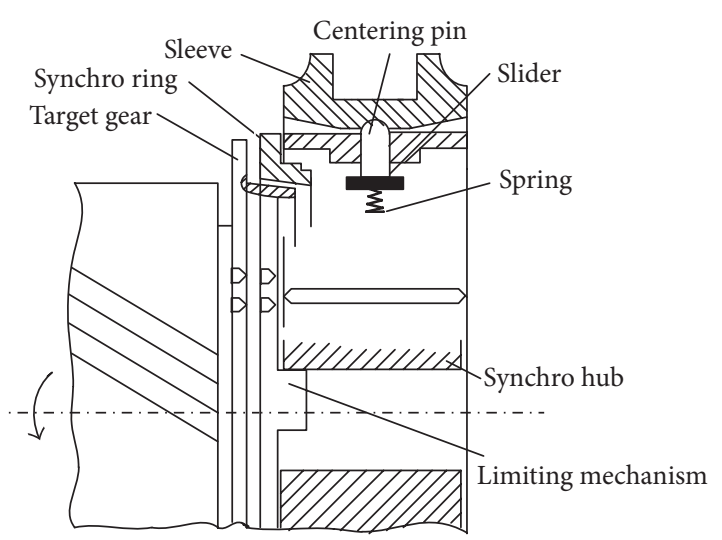

Figure 7: First free fly.

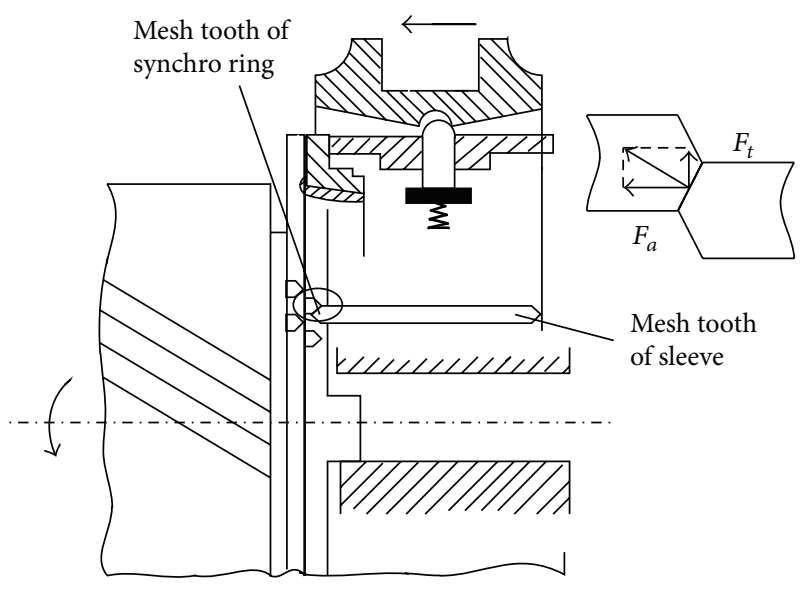

FIGURE 8: Angular velocity synchronization.

In the sleeve deceleration stage one has

$$
F_{j} t=m_{s} v_{s}
$$

where $F_{j}$ is the impact force acted on meshing teeth of synchro ring from sleeve, $t$ is the sleeve deceleration time, and $v_{s}$ is the axial velocity of sleeve under the shifting force.

In the sliding friction stage one has

$$
\begin{gathered}
T_{s}=F_{x} * f * \frac{r}{\sin \alpha}, \\
P_{s}=T_{s}\left|\omega_{o}-\frac{\omega_{i}}{i_{g}}\right|,
\end{gathered}
$$

where $F_{x}$ is the axial force of sleeve, $f$ is the friction coefficient, $r$ is the mean effective cone radius, $\alpha$ is half of the cone angle, and $P_{s}$ is the friction power.

5.4.3. Turning the Synchro Ring. When the two parts of synchronizer have been synchronized, the driving part rotates under the action of the sleeve teeth (the driven part connects rigidly to the vehicle body, so it cannot be turned). A low angular velocity differential between sleeve and synchro ring occurs with the turning of synchro ring. Then the synchronization is broken up and the locking state of synchro ring

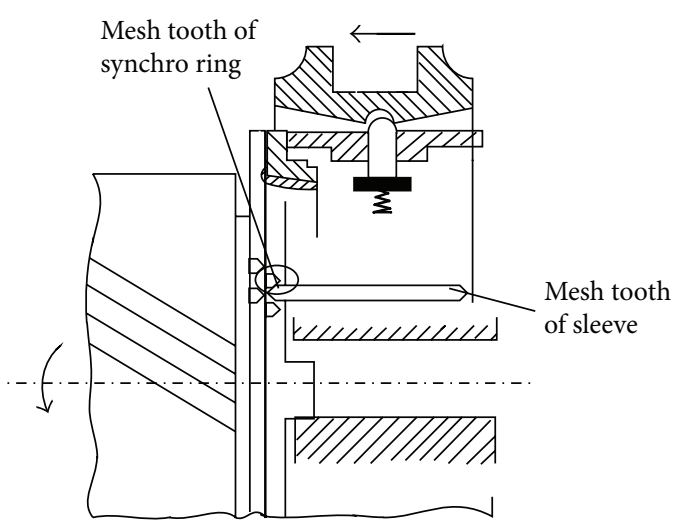

Figure 9: Turning the synchro ring.

disappears. The schematic diagram of this stage is shown in Figure 9.

Before the turning one has

$$
\omega_{r 0}=\omega_{o}
$$

During the turning process one has

$$
\begin{gathered}
F_{x} \frac{1-\mu \tan \beta}{\mu+\tan \beta} r_{s}-T_{\text {loss }}-T_{i} i_{g}-T_{f}=J_{r} \dot{\omega}_{r} \\
J_{r}=J_{e+c}+J_{m+c}+J_{i}, \\
\omega_{r 1}=\omega_{r 0}+\dot{\omega}_{r} t \\
\omega_{r 1} \neq \omega_{o},
\end{gathered}
$$

where $\omega_{r 0}$ is the initial angular speed of synchronizer driving part before rotation, $\omega_{o}$ is the speed of output shaft, $\omega_{r 1}$ is the input speed after rotation, $\beta$ is the angle of roof shape at the interlock gearing, $\mu$ is the friction coefficient at roof-shaped edge, $r_{s}$ is the mean effective radius on interlock gearing, $T_{\text {loss }}$ is the moment of losses, $T_{i}$ is the input torque, $J_{r}$ is the equivalent inertia to the synchronizer input end, and $\dot{\omega}_{r}$ is the angular acceleration of synchronizer input part.

5.4.4. Turning the Target Gear. This stage starts from the separation of synchro ring and cone surface of the target gear. The driving part of the synchronizer including the synchro ring rotates under the action of the sleeve teeth. It ends at the beginning of eventual slide. The schematic diagram of this stage is shown in Figure 10.

During this stage one has

$$
\begin{gathered}
F_{x} \frac{1-\mu \tan \beta}{\mu+\tan \beta} r_{s}-T_{\text {loss }}-T_{i} i_{g}-T_{f}=\left(J_{r}+J_{s}\right) \dot{\omega}_{r}, \\
\omega_{r 2}=\omega_{r 1}+\dot{\omega}_{r} t
\end{gathered}
$$

where $J_{s}$ is the rotational inertia of synchro ring.

5.4.5. Final Free Fly. The sleeve engages with the target gear under the action of the gear shifting force. The kinetic 


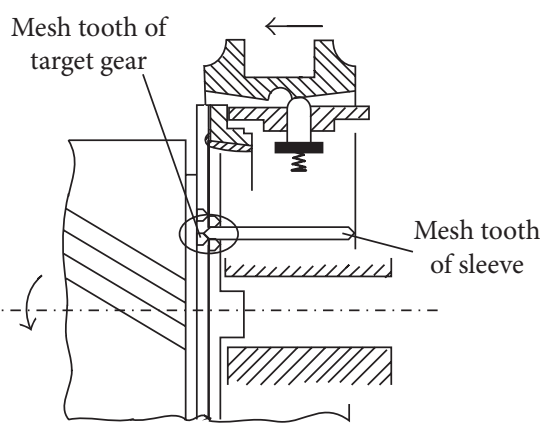

FIGURE 10: Turning the target gear.

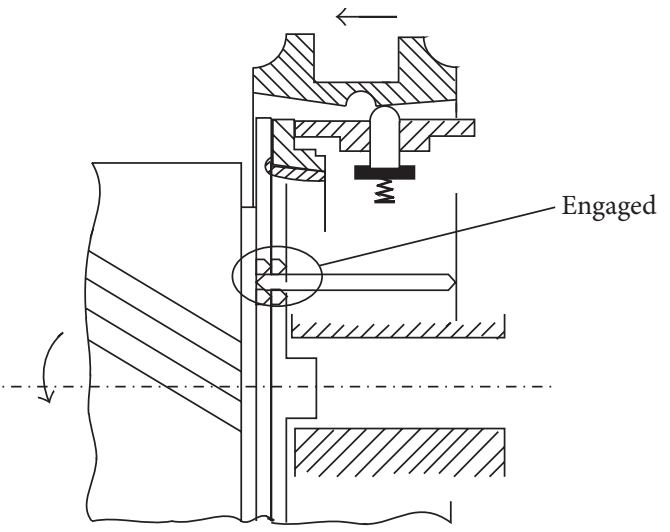

FIgURE 11: Final free fly.

equation is similar to the first stage. The schematic diagram of this stage is shown in Figure 11. Consider

$$
\begin{gathered}
F_{x}-F_{f}-F_{r}=m_{s} \dot{a}_{s}, \\
F_{f}=\frac{\mu_{g} T_{i} i_{g}}{r_{s}},
\end{gathered}
$$

where $\mu_{g}$ is the axial dynamic friction coefficient between sleeve and spline teeth of constant mesh gear and $T_{i}$ is the transferred torque. We can get the conclusion from the derived kinetic equations that in the gear shifting process without disengaging clutch for a parallel hybrid vehicle equipped with AMT, the inertia of input shaft, the speed control precision of driving motor, and the input torque of transmission can directly affect the synchronization time and friction work. The control of shifting force is also very important. An ideal control of each component in each stage can improve the quality of gear shifting and increase the life of synchronizer.

\section{Coordinated Control of Each Component in Each Stage of a Gear Shifting Process}

6.1. Switch to Neutral Gear. The necessary condition of switching to neutral gear is

$$
F_{x}>F_{f}=\frac{\mu_{g} T_{i} i_{g}}{r_{s}},
$$

where the input torque of the power sources is

$$
T_{i}=T_{e}+T_{m}-T_{f}-T_{e m}
$$

Obviously, the reasonable control of gear shifting force and the input torque is the precondition to disengage the gears smoothly. And the basic rules are to increase the gear shifting force $F_{x}$ and decrease the input torque $T_{i}$.

But the force to disengage the gears cannot increase infinitely, and the exceeding force might damage the surface of meshing teeth; therefore, it should be controlled within the stipulated limit. The key to disengage the gears smoothly is to control the input torque close to zero. In order to realize this control, we measured and got the input torque characteristics curve of the power sources as well as the friction torque characteristics curve of the driving part, then established the actual net output of torque model.

In this paper, we control the engine torque to zero and the friction torque of the input part of the system is compensated by the electrical motor to achieve a zero net output torque of the power system; the control law is represented as

$$
T_{i}=f\left(\alpha_{e}, T_{m}, \omega_{i}\right)
$$

Another problem is the coordinated torque control of the two power sources during the unloading phase. The control parameters during the unloading phase involved the engine throttle opening $\alpha_{e}$ and motor torque $T_{m}$. Firstly, the torque $T_{i}$ should be adjusted linearly instead of step change. Secondly, the gear shifting time should be as short as possible. Finally, the input torque $T_{i}$ should be controlled close to zero.

The engine throttle opening is controlled linearly to zero without step change. The step change might cause the shaft torsional vibration between the engine and the driving motor; it also might influence the driving motor.

Bench test showed that if the unloading time of the engine is $0.8 \mathrm{~s}$ when the initial throttle opening is $100 \%$, the shaft torsional vibration between the engine and motor can be negligible. When the hybrid power system starts to unload linearly from the maximum torque $1200 \mathrm{Nm}$ and the unload speed is $15 \mathrm{Nm} / 10 \mathrm{~ms}$, the shaft torsional vibration of the transmission system can be negligible as well. So $0.8 \mathrm{~s}$ is the maximum unloading time. The PMSM can respond much faster than engine; it can be controlled to compensate the resistance torque and adjust the input torque $T_{i}$ to zero linearly during the process of the engine unloading. 


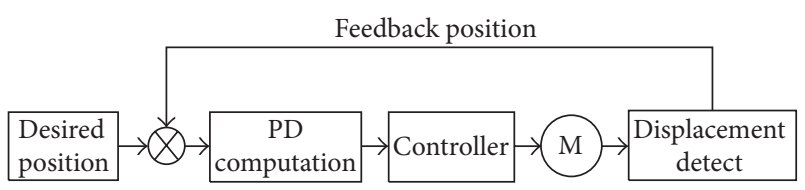

FIGURE 12: The diagram block of gearshift BLDCM controller.

The target throttle opening during the phase of engine unloading is

$$
\begin{array}{r}
\alpha_{i+1}=\alpha_{i}-1 \quad\left(i_{\min }=1, i_{\max }=\alpha_{e_{\text {init }}}\right) \\
\text { if }\left(\alpha_{i}<1\right) \alpha_{i}=0
\end{array}
$$

where $\alpha_{i}$ is the throttle opening percentage of the CAN protocol, its physical values range from 0 to 100 , and its resolution is 0.1 and $i_{\max }$ is the total unload steps equal to the initial physical values of $\alpha_{i}$ before unloading. The time interval between $\alpha_{i+1}$ and $\alpha_{i}$ is $10 \mathrm{~ms}$, which is transmitted to the engine control unit (ECU) by transmission control unit (TCU) via CAN bus.

Without considering the effect of temperature, the relationship between friction torque and rotation speed of input shaft when the clutch is engaged can be given as

$$
T_{f}=f\left(n_{i}\right)
$$

The target control torque of the motor is

$$
T_{m}(i+1)=T_{m_{\mathrm{init}}}+\frac{\left(T_{f}-T_{m_{\mathrm{init}}}\right)}{i_{\max }},
$$

where $i_{\max }$ is the total unload step and its value is equal to the initial physical value of $\alpha_{i}$ before unloading.

When $T_{i} \in(-15 \mathrm{Nm}, 15 \mathrm{Nm})$, the BLDCM can start to drive the gearshift actuator to disengage the gears. To get an accurate control position of the gearshift actuator and a smooth gearshift, the displacement of the actuator is chosen as feedback of the BLDCM control. The closed loop proportional-derivative (PD) control is chosen as the control strategy of gear selecting and shifting motor; the relationship between input $e(t)$ and output $u(t)$ after discretization is given as

$$
u(k)=K_{p} e(k)+K_{d}[e(k)-e(k-1)],
$$

where $K_{d}, K_{p}$ are the differential coefficient and proportional coefficient of the controller, respectively; $e(k)$ is the deviation of current detecting position and the desired position; $u(k)$ is the output value of the controller after $k$ times sampling and calculating. The diagram block gearshift BLDCM controller is shown in Figure 12.

\subsection{Switch to a Certain Gear}

6.2.1. Active Speed Synchronous Control Driving by PMSM. In this stage, the gearbox is in neutral gear, the driving motor is controlled in speed control mode, and its speed should be adjusted to

$$
n_{m_{\text {aim }}}=n_{o} \cdot i_{g}
$$

When $n_{m} \in\left(n_{m_{\text {aim }}}-20, n_{m_{\text {aim }}}+20\right)$, the system starts to execute the next action. In addition, to reduce the entire gear shifting time further, the gear selecting actuator can be simultaneously controlled during the process of speed adjusting.

6.2.2. Mechanical Synchronization and Gear Engaging Process. The PMSM should be controlled to follow the speed of output shaft, after the active speed synchronous control, the gearshift actuator starts to engage the target gears.

(1) First Free Fly. This stage should be finished quickly and need a larger gear shifting force, but the force cannot be infinitely increased because excessive shift force may cause large impact force $F_{j}$, and reduce the life of synchro ring and sleeve.

(2) Angular Velocity Synchronization. In this stage, the BLDCM torque is directly controlled to an allowed maximum value to finish the mechanical synchronization process as soon as possible. The driving motor is still controlled in speed mode following the speed of output shaft in this stage, which could eliminate the rotation speed difference caused by the road condition or braking action timely; it can help to reduce the sliding friction work and the synchronization time.

(3)Turning the Synchro Ring. The control of this phase is the key to engage the gears successfully and quickly; we can know from (20) that to turn the synchro ring and unlock the synchronizer, the gearshift torque should overcome the torque loss $T_{\text {loss }}$, the input torque of power sources $T_{i} i_{g}$, and the friction torque of transmission input side $T_{f}$.

Real road test also confirmed that it was difficult to overcome the resistance torque $T_{i}$ (approximately $100 \mathrm{Nm}$ ) depending on the gearshift torque which is limited using a fixed threshold. The target gears cannot be engaged for quite a long time after finishing the rotation speed synchronization process. However, it is obvious that the input torque of power sources $T_{i} i_{g}$ is also controllable in this stage. The engine is working in the idle state now, which can be considered as the load of transmission system. The driving motor is in control phase of following the speed of output shaft. Based on this point of view we proposed a control method called "actively unlock the synchronizer control" after finishing the speed synchronization.

The specific control method is to control the driving motor has a jagged speed fluctuation ranging from $-10 \mathrm{rpm}$ to $10 \mathrm{rpm}$ after the mechanical synchronization, which can make the sleeve teeth wriggle between teeth of synchro ring, so the synchro ring can be turned with the help of active control of 
PMSM and gear shifting force. The basic principle is shown in Figure 13.

(4) Turning the Target Gear. This stage is almost the same as the last one except that the synchro ring is unlocked. The actual wriggled components are still in the sleeve side; the control algorithm can be learned from the previous stage.

(5) Final Free Fly. In this stage, the gear shift actuator is controlled to the desired position and the engaging process is finished.

6.3. Torque Recovering. After a successful gear shifting, the torque of the engine and driving motor should be controlled to the desired value of the driver separately without large torsional vibration and long time power interrupt. The control algorithm is shown in Figure 14.

\section{Bench Test and Road Test}

The block diagram of the overall gear shifting control algorithm for a single-shaft parallel HEV equipped with AMT without disengaging clutch is shown in Figure 15.

In the bench the eddy current dynamometer works in the load following mode that can simulate the actual driving test cycle conditions. The monitor system of dynamometer can display the output torque of power sources in real time, and it can detect the jerk of output shaft when engagement or disengagement happens. The main purpose of the bench test is to verify and modify the control strategy. Figure 16 is a picture of the test bench.

After plenty of bench test, 1000 kilometers real road test with a real HEV was conducted. Figure 17 shows the test HEV.

Figure 18 represents some exemplary curves of gear shifting process in road test. when stage (1) is the unload stage, the engine is unloading exactly to maintain its idle state, and the driving motor is unloading to the torque that can just overcome the friction torque of the power input side; this stage costs about $0.3 \mathrm{~s}$. Then, the gears are disengaged within $0.2 \mathrm{~s}$. In stage (3), the driving motor is controlled in speed mode to finish the active synchronization process which costs about $0.4 \mathrm{~s}$. In stage (4), the target gears are successfully and quickly engaged with the small speed oscillation driven by the motor after the mechanical synchronization; this stage costs about $0.2 \mathrm{~s}$. The whole gear shifting process costs about $1 \mathrm{~s}$.

Figure 19 shows that the torque of engine and driving motor transits to the driver's desired torque smoothly when the demand torque is recovering after a gearshift. And this stage costs about $0.5 \mathrm{~s}$.

\section{Conclusions}

In this paper, mathematical models of every component for a HEV are described, derivation and analysis of the gear shifting dynamics model in every working process of the synchronizer is also given. Innovative control strategies including dynamic coordinated control in powertrain unload

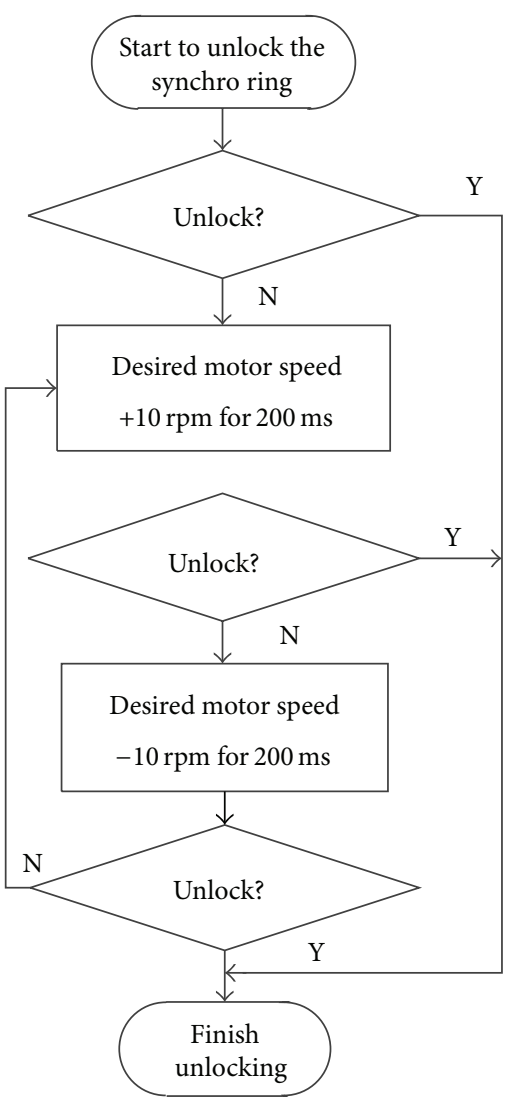

FIGURE 13: The algorithm to unlock the synchronizer actively.

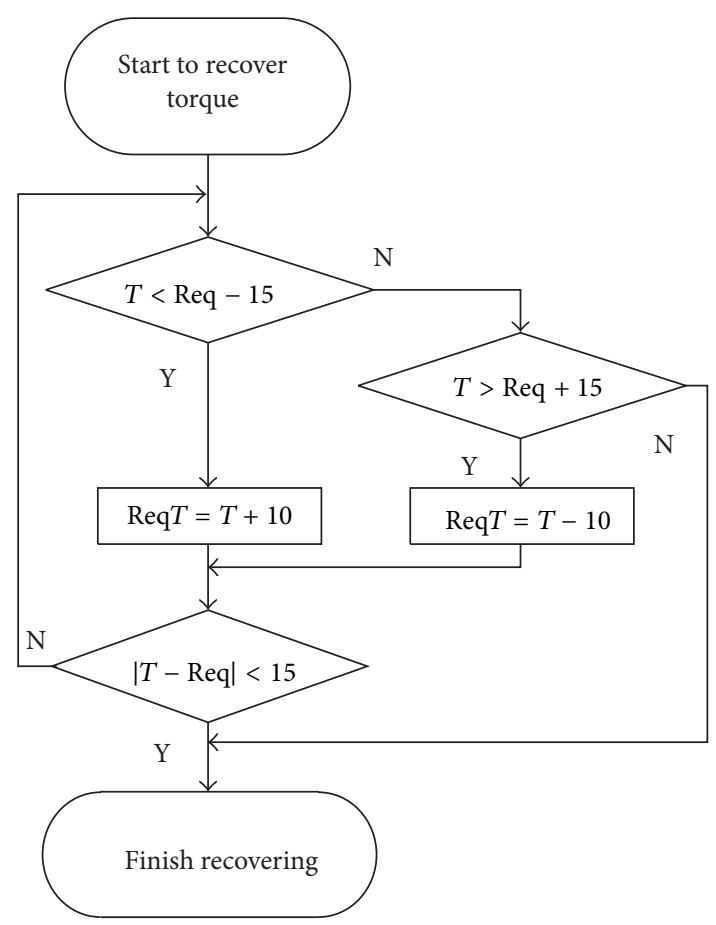

FIGURE 14: The algorithm of recovering torque. 
TABLE 2: The statistical data of evaluation indexes in road test.

\begin{tabular}{lcccccccc}
\hline Stage & 1 & 2 & 3 & 1 & 2 & 3 & 1 & 2 \\
\hline Input shaft speed $(\mathrm{r} / \mathrm{min})$ & 1560 & - & 907 & 1049 & - & 799 & 1675 & - \\
Maximum jerk $\left(\mathrm{m} / \mathrm{s}^{3}\right)$ & 11.5 & - & 5 & 12.3 & - & 5.4 & 9 & - \\
Stage time $(\mathrm{ms})$ & 329 & 488 & 549 & 368 & 414 & 560 & 366 & 480 \\
Total time $(\mathrm{ms})$ & & 1353 & & & 1321 & & 569 \\
\hline
\end{tabular}

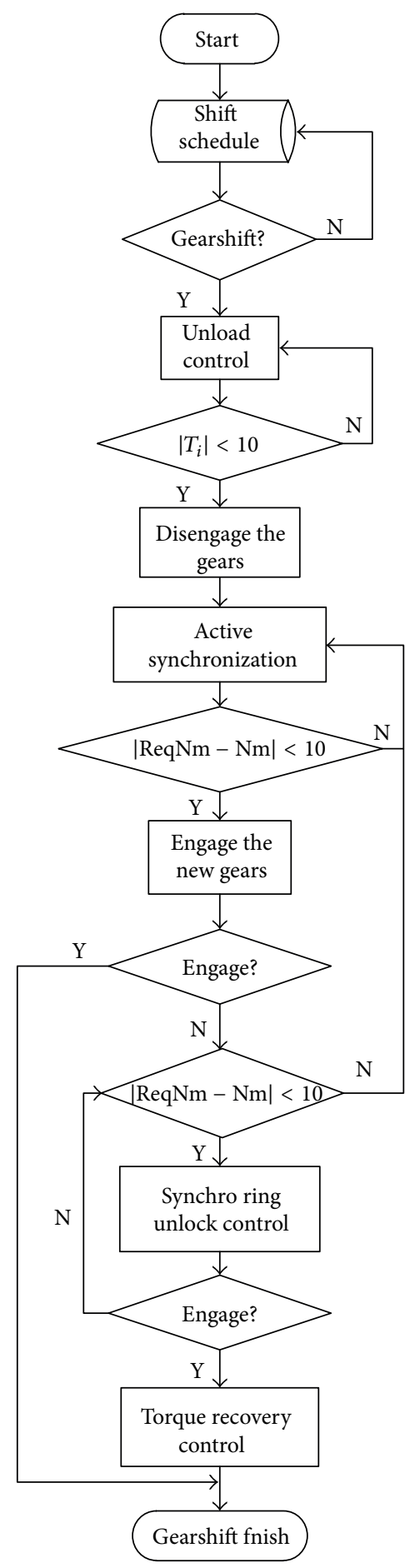

FIGURE 15: Gear shifting control algorithm for a single-shaft parallel HEW without disengaging clutch.

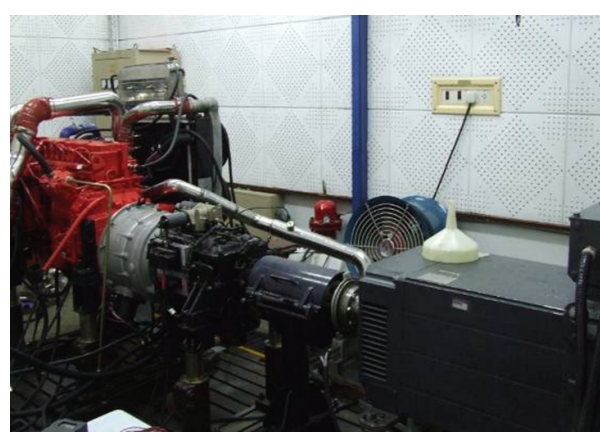

Figure 16: The test bench.

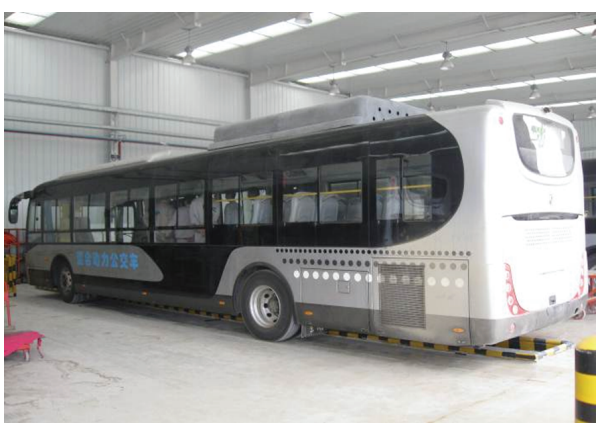

Figure 17: The test HEV.

process and active unlock control of the synchronizer on a HEV are proposed.

By the dynamic coordinated control of the engine, motor and actuators in unloading process, the net input torque of the gearbox can be controlled more closely to zero, and it is easy to disengage the gears smoothly and quickly. By the dynamic coordinated control of the engine, motor, and actuators in every working stage of the synchronizer during a gear shifting process, the gears can be controlled to engage more quickly and successfully with less friction.

According to the statistical data of the evaluation indexes in Table 2, the whole gear shifting time is controlled within $1.5 \mathrm{~s}$. And the time consuming for stage 1 (disengaging the gears) and stage 2 (recovering the torque) takes about 50\% of the whole gear shifting time, which is determined by the gearshift points and the driver's demand of torque. The power interrupt time is controlled within $0.5 \mathrm{~s}$ and the dynamic property of the HEV is ensured. The jerk of gear shifting without disengaging clutch is controlled within $15 \mathrm{~m} / \mathrm{s}^{3}$ and the ride comfort of the HEV is ensured. 

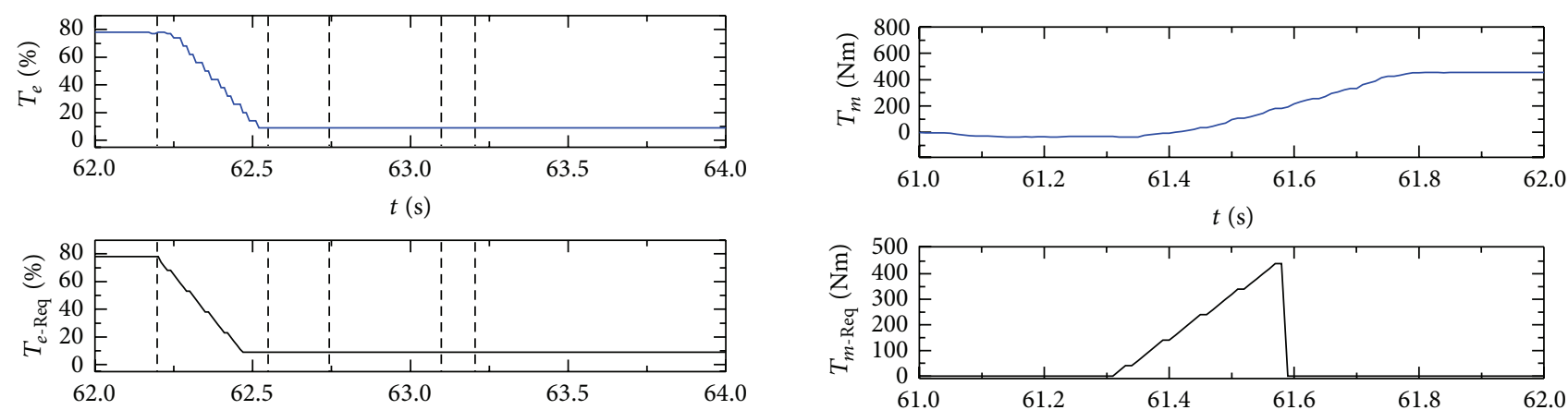

$t(\mathrm{~s})$
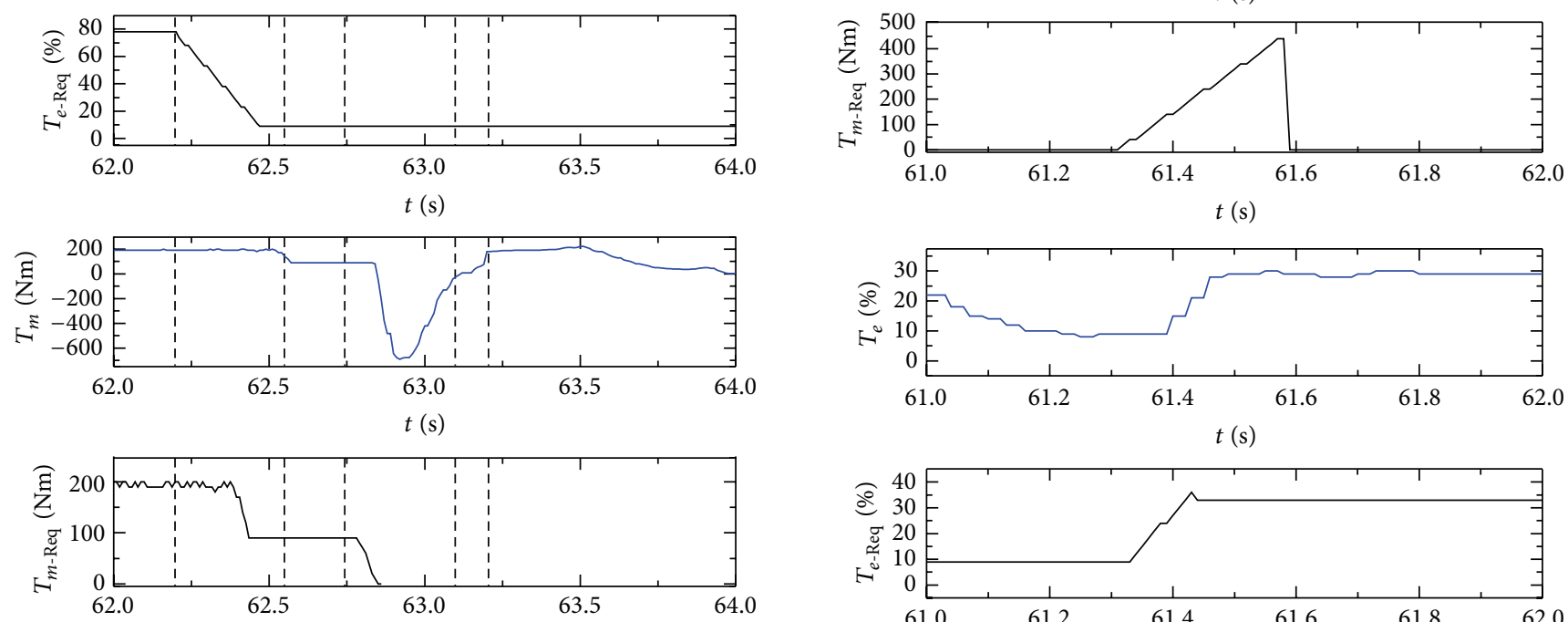

$t(\mathrm{~s})$
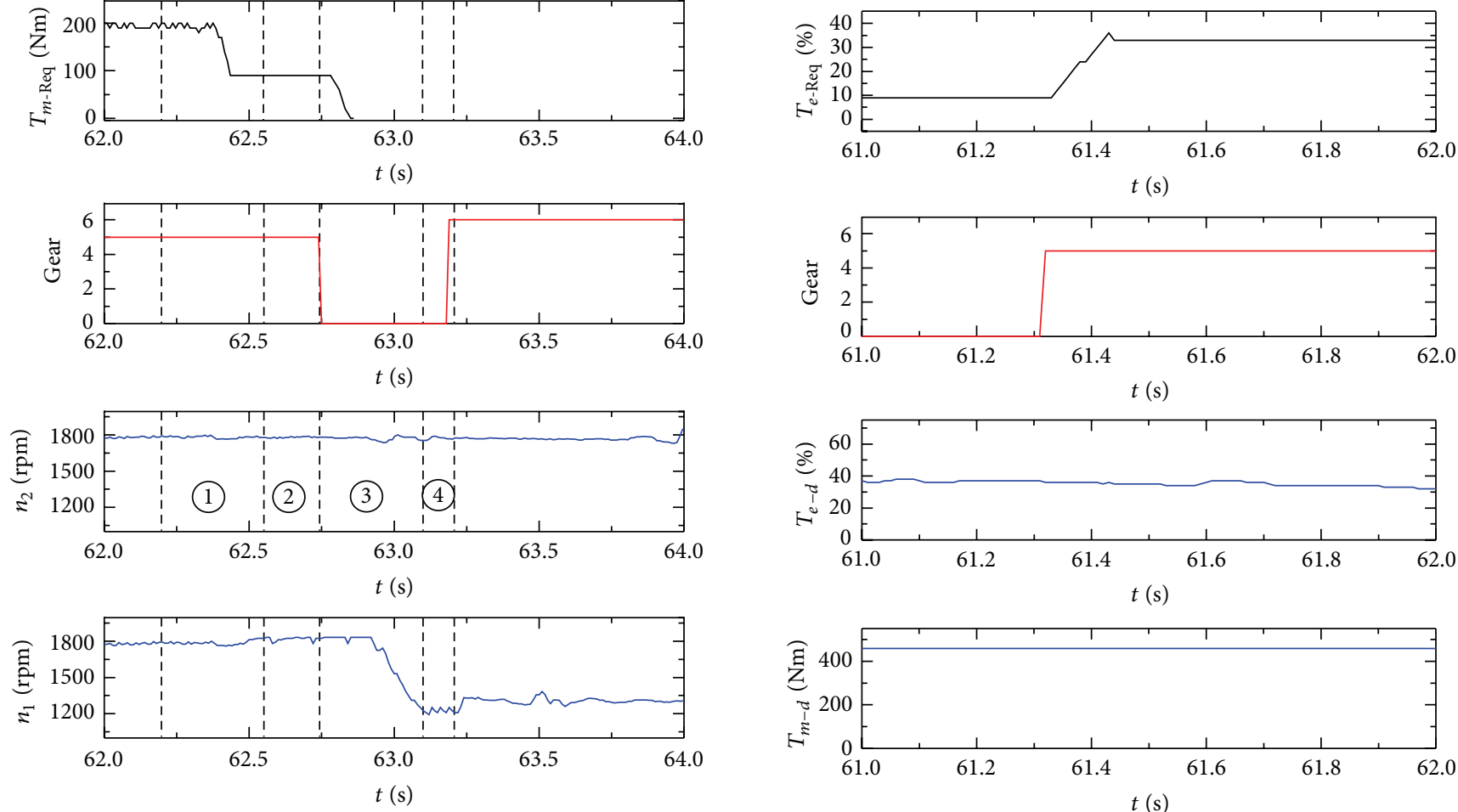

FIGURE 18: Experiment curves of a gear shifting process.

The proposed gear shifting control strategy can also be applied into other kinds of pure electric or hybrid electric vehicles with similar gear box to significantly improve the gear shifting quality in all its evaluation indexes. Control strategy using more advanced control technologies $[15,16]$ will be proposed to improve the gear shifting quality further in the near future.

\section{Conflict of Interests}

The authors declare that there is no conflict of interests regarding the publication of this paper.

\section{Acknowledgment}

This work was supported by the National High Technology Research and Development Program of China (Grant no. 2011AA11A223).

\section{References}

[1] M. Pettersson and L. Nielsen, "Gear shifting by engine control," IEEE Transactions on Control Systems Technology, vol. 8, no. 3, pp. $495-507,2000$. 
[2] L. Glielmo, L. Iannelli, V. Vacca, and F. Vasca, "Gearshift control for automated manual transmissions," IEEE/ASME Transactions on Mechatronics, vol. 11, no. 1, pp. 17-26, 2006.

[3] Y. Lei, M. Niu, and A. Ge, "A research on starting control strategy of vehicle with AMT," in Proceedings of the FISITA World Automotive Congress, Seoul, Korea, 2000.

[4] H. Lee, S. Sul, H. Cho, and J. Lee, "Advanced gear-shifting and clutching strategy for a parallel-hybrid vehicle," IEEE Transactions on Industry Applications, vol. 6, no. 6, pp. 26-32, 2000.

[5] U. Kiencke and L. Nielsen, Automotive Control Systems: For Engine, Driveline, and Vehicle, Springer, 2nd edition, 2005.

[6] Z. Zhong, G. Kong, Z. Yu, X. Xin, and X. Chen, "Shifting control of an automated mechanical transmission without using the clutch," International Journal of Automotive Technology, vol. 13, no. 3, pp. 487-496, 2012.

[7] X. T. Lu and G. Z. Hou, "Introduction of the AMT control system structure and main foreign AMT products," Automobile Technology, vol. 5, pp. 19-22, 2004 (Chinese).

[8] R. C. Baraszu and S. R. Cikanek, "Torque fill-in for an automated shift manual transmission in a parallel hybrid electric vehicle," in Proceedings of the American Control Conference, vol. 8-10, pp. 1431-1436, Anchorage, Alaska, USA, May 2002.

[9] C. L. Liao, J. Z. Zhang, and Q. C. Lu, "Coordinated powertrain control method for shifting process of automated mechanical transmission in the hybrid electric vehicle," Journal of Mechanical Engineering, vol. 41, no. 12, pp. 37-41, 2005 (Chinese).

[10] M. Ye, D. T. Qin, and Z. J. Liu, "Shift performance control for mild hybrid electric vehicle equipped with automatic manual transmission," Journal of Mechanical Engineering, vol. 45, no. 5, pp. 108-114, 2009 (Chinese).

[11] J. Fredriksson and B. Egardt, "Nonlinear control applied to gearshifting in automated manual transmissions," in Proceedings of the 39th IEEE Confernce on Decision and Control, pp. 444-449, Sydney, Australia, December 2000.

[12] X. Dong, Dynamic control of engine and motor in a gearshift for HEV equipped with AMT [Ph.D. thesis], Beijing Institute of Technology, 2012.

[13] L. Guo, A. Ge, T. Zhang, and Y. Yue, "AMT shift process control," Transactions of the Chinese Society for Agricultural Machinery, vol. 34, no. 2, pp. 1-10, 2004.

[14] L. Lovas, D. Play, J. Marialigeti, and J. F. Rigal, "Mechanical behaviour simulation for synchromesh mechanism improvements," Proceedings of the Institution of Mechanical Engineers, Part D, vol. 220, no. 7, pp. 919-945, 2006.

[15] H. Zhang, Y. Shi, and M. X. Liu, " $H_{\infty}$ step tracking control for networked discrete-time nonlinear systems with integral and predictive actions," IEEE Transactions on Industrial Informatics, vol. 9, no. 1, pp. 337-345, 2013.

[16] H. Zhang, Y. Shi, and A. S. Mehr, "Robust static output feedback control and remote PID design for networked motor systems," IEEE Transactions on Industrial Electronics, vol. 58, no. 12, pp. 5396-5405, 2011. 


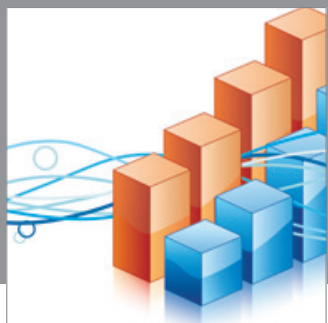

Advances in

Operations Research

mansans

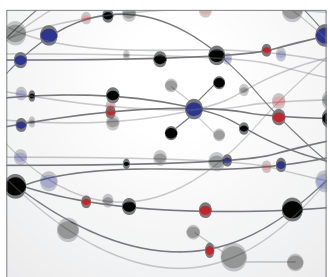

The Scientific World Journal
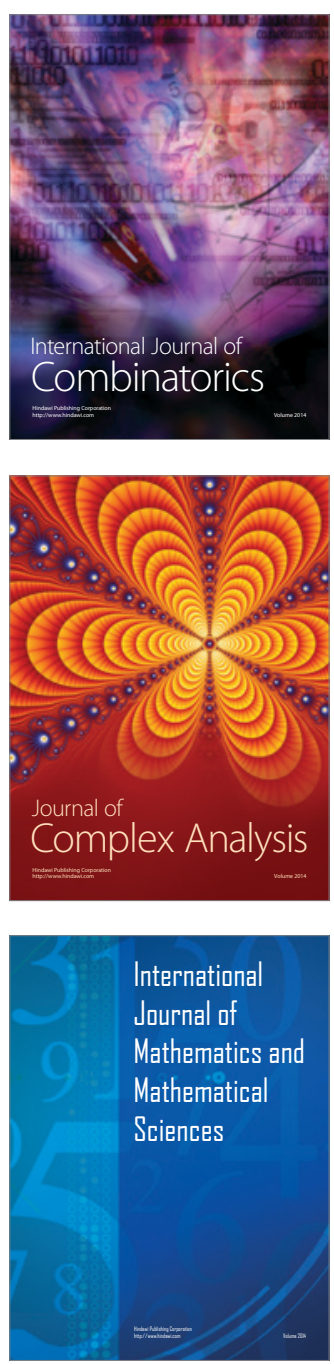
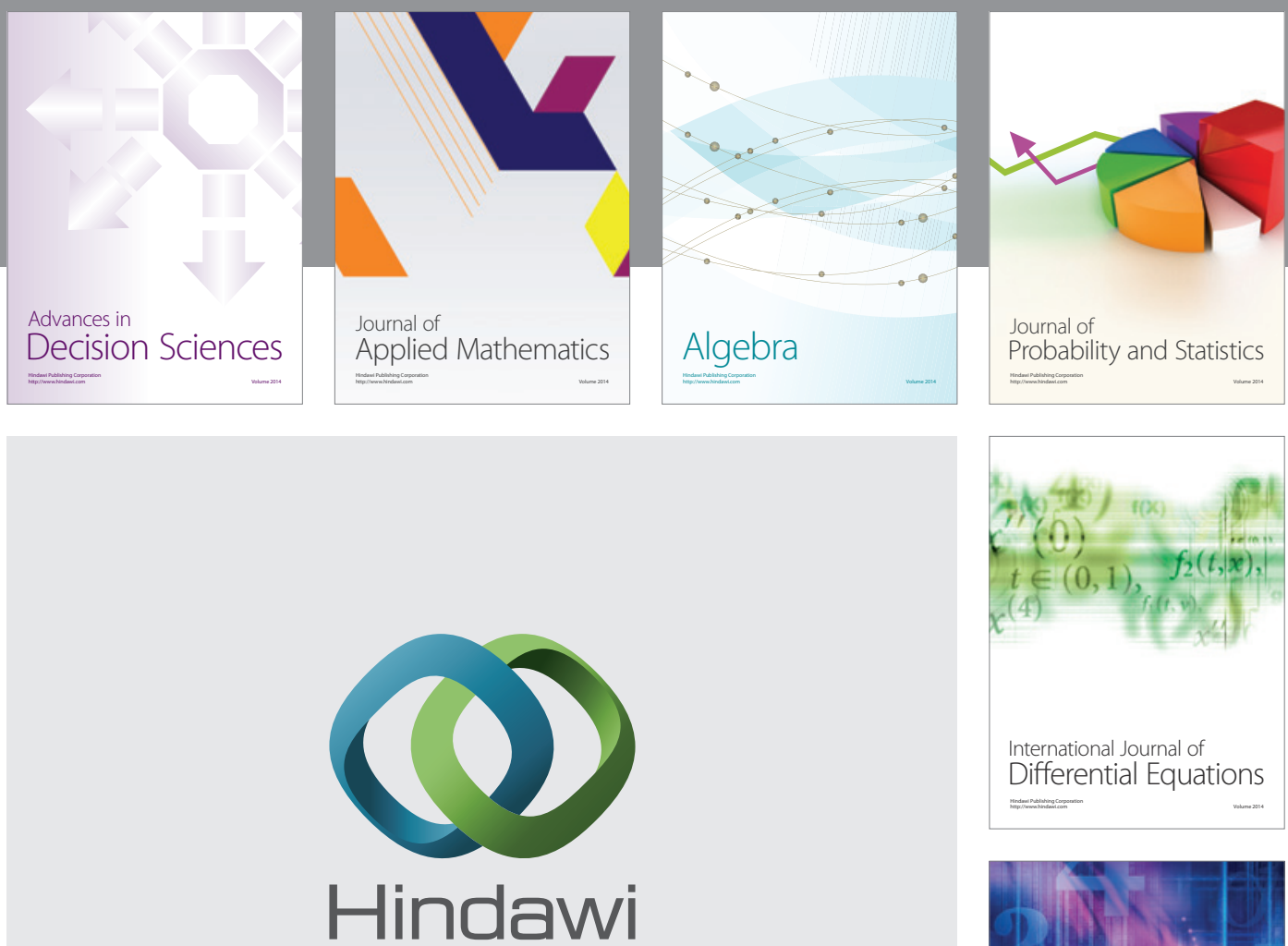

Submit your manuscripts at http://www.hindawi.com
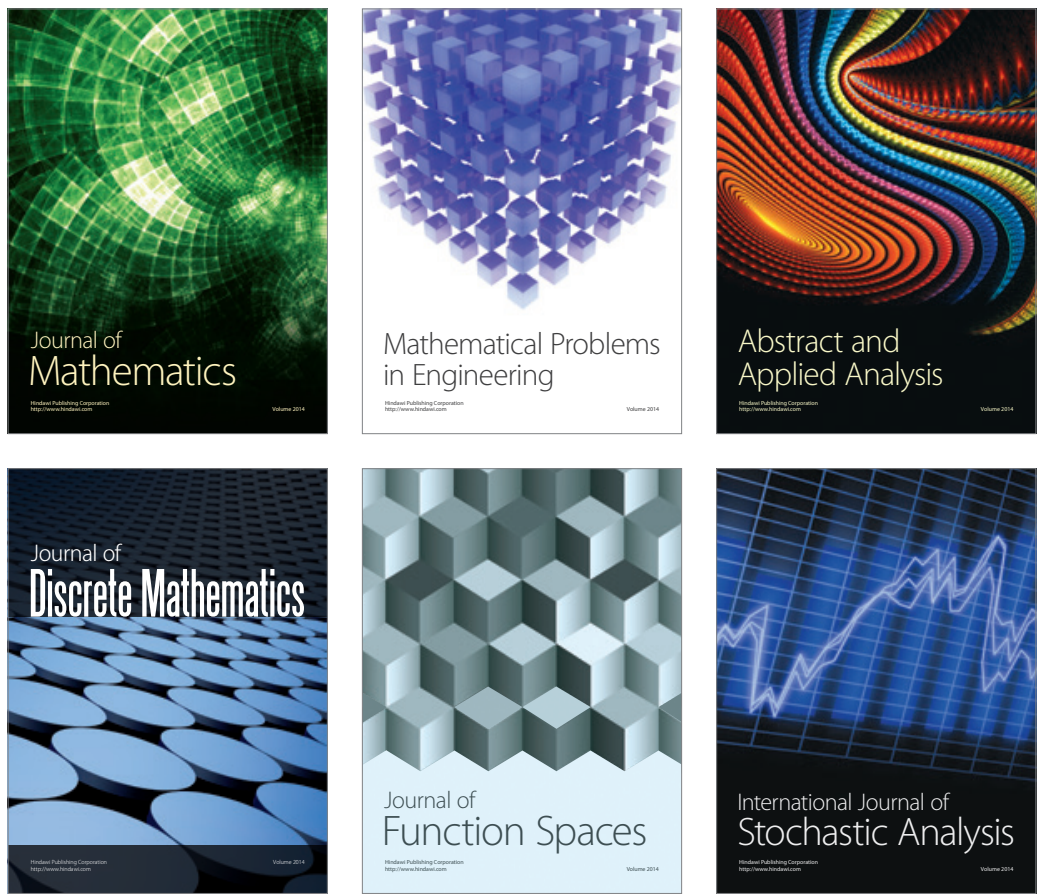

Journal of

Function Spaces

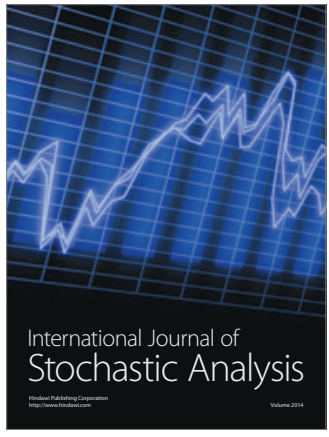

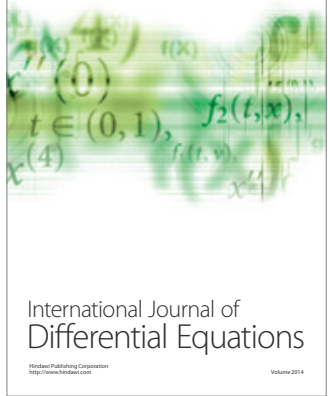
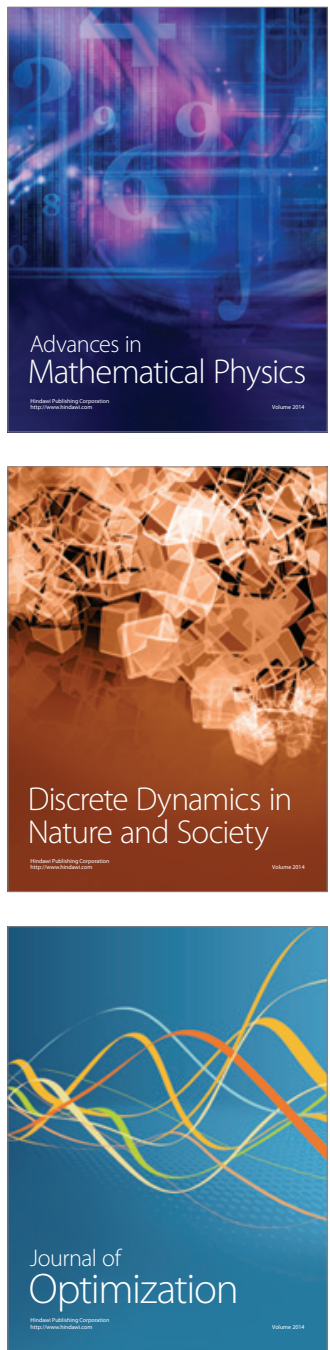